UDC 316.472 .4

LBC 60.561.6

\title{
THE RATIO OF NEGATIVE AND POSITIVE INFLUENCE FACTORS OF THE URBAN ENVIRONMENT ON THE URBANITES' HEALTH
}

\author{
Evgeniy G. Vershinin \\ Volgograd State Medical University, Volgograd, Russian Federation \\ Mikhail A. Sukhoruchko \\ Volgograd State Medical University, Volgograd, Russian Federation \\ Gennadiy Yu. Shchekin \\ Volgograd State Medical University, Volgograd, Russian Federation
}

\begin{abstract}
The impact of the urban environment on health is recognized by many authors as negative. But the positive effects of this influence cannot be overemphasized. One of them is the availability of a system of highquality medical care. The paradox is that by experiencing constant physiological, psychological, intellectual overload, suffering from hypodynamia and adverse environmental background urban residents have a wide range of preventive, curative and rehabilitative health services. The authors conducted a study on the model of the musculoskeletal system diseases affecting mainly urban residents and found out that such a phenomenon as the competition of private and public medicine in the fight against these diseases in the urban environment gives a positive effect. Research has shown that the conditions of the urban environment themselves are not clearly bad or good for health. The vector of their influence depends on the choice of the person who can take advantage of the opportunities provided by the city for health promotion or passively obey the negative influences of the urban environment. Urban residents have ample opportunities to choose the health-improving methods provided by clinics and centers of restorative medicine of private ownership. But commercial interests in this case may contradict the goals of recreational activities. The state should not hinder the development of private medicine, it needs to embrace social technologies of healthy lifestyle among the population. The provision of medical services cannot be based on the postulate of self-regulation of the market, because the appeal of a person for help in a private clinic is most often associated not with financial considerations, but with personal medical experience, the influence of relatives, friends, the media, Internet information, self-assessment of health. survey.

Key words: urban environment, health, diseases of the musculoskeletal system, private clinic, paid services, УДК 316.472 .4

ББК 60.561 .6

СООТНОШЕНИЕ НЕГАТИВНЫХ И ПОЗИТИВНЫХ ФАКТОРОВ ВЛИЯНИЯ ГОРОДСКОЙ СРЕДЫ НА ЗДОРОВЬЕ ЖИТЕЛЕЙ
\end{abstract}

\section{Евгений Геннадьевич Вершинин}

Волгоградский государственный медицинский университет, г. Волгоград, Российская Федерация

Михаил Александрович Сухоручко

Волгоградский государственный медицинский университет, г. Волгоград, Российская Федерация

Геннадий Юрьевич Щекин

Волгоградский государственный медицинский университет, г. Волгоград, Российская Федерация 
Аннотация. Влияние городской среды на здоровье многими авторами признается негативным. Но позитивные эффекты этого влияния нельзя не признавать. Одним из них является наличие системы качественной медицинской помощи. Парадокс состоит в том, что, испытывая постоянные физиологические, психологические, интеллектуальные перегрузки, страдая от гиподинамии и неблагоприятного экологического фона, городские жители имеют широкий выбор профилактических, лечебных и реабилитационных медицинских услуг. Авторы провели исследование на модели заболеваний опорно-двигательного аппарата, которыми страдают преимущественно городские жители, и выяснили, что такой феномен, как конкуренция частной и государственной медицины в борьбе с этими заболеваниями, в условиях городской среды дает положительный эффект. Исследование показало, что сами по себе условия городской среды не являются однозначно плохими или хорошими для здоровья. Вектор их влияния зависит от выбора человека, который может воспользоваться предоставляемыми городом возможностями для укрепления здоровья или пассивно подчиниться негативным влияниям городской среды. Городские жители имеют широкие возможности для выбора оздоровительных методик, предоставляемых клиниками и центрами восстановительной медицины частной формы собственности. Но коммерческие интересы в данном случае могут вступить в противоречие с целями оздоровительных мероприятий. Государство не должно препятствовать развитию частной медицины, оно должно шире внедрять социальные технологии здорового образа жизни среди населения. При оказании медицинских услуг нельзя исходить из постулата о саморегуляции рынка, поскольку обращение человека за помощью в частную клинику чаще всего связано не с финансовыми соображениями, а с личным медицинским опытом, влиянием родных, друзей, СМИ, интернет-информации, самооценкой состояния здоровья.

Ключевые слова: городская среда, здоровье, болезни опорно-двигательного аппарата, частная клиника, платные услуги, анкетирование.

Влияние городской среды на здоровье человека изучено достаточно полно, хотя основной массив научной литературы по этому вопросу посвящен влияниям негативным, тогда как охранные и жизнеобеспечивающие функции города обсуждаются менее широко [9]. В этом аспекте нам ближе позиция тех авторов, которые признают баланс позитивных и негативных факторов влияния городской среды на здоровье человека. Так, Ю.М. Комаров и И.Н. Веселкова пишут: «В крупных городах переплелись как положительные, так и отрицательные стороны научно-технического прогресса и индустриализации. Совокупность факторов окружающей среды (природных, социально-экономических, хозяйственно-бытовых, антропогенных) может воздействовать на все население, отдельные его группы и на каждого человека как однонаправленно (в положительную или отрицательную сторону), так и разнонаправленно» [5].

Чаще всего к патогенным факторам городской среды причисляют следующие: экологические, бытовые, информационные, производственные, коммуникативные. При этом отмечаются такие особенности их действия, как высокая плотность населения, загрязнение атмосферы, низкая двигательная активность горожан, связанная как с образом жизни, так и с характером труда, режим питания.
Соответственно, номенклатура заболеваний, вызванных этими факторами и условиями их воздействия на человека, включает инфекционные, сердечно-сосудистые, нервно-психические, аллергические, онкологические заболевания. Подробная характеристика этих процессов представлена в публикациях журнала «Социология города» $[1 ; 4 ; 6 ; 12]$. Обсуждению негативного влияния факторов городской среды на здоровье были посвящены также многие материалы журнала «Биоэтика» [7; 10; 14; 16]. В этих и других подобных публикациях мы не нашли информации о соотношении позитивных и негативных эффектов влияния городской среды на здоровье, поэтому решили рассмотреть данный вопрос подробнее на примере заболеваний, которые во многом спровоцированы условиями жизни и работы именно в городе, но о которых в таком аспекте практически не говорится. Речь идет о заболеваниях опорно-двигательного аппарата.

Болезни опорно-двигательного аппарата являются одними из самых распространенных заболеваний. Они оказывают существенное влияние на здоровье и качество жизни и налагают огромное бремя расходов на систему здравоохранения. По данным National Health Interview Survey (NHIS), в США в 2012 г. было зафиксировано 126,6 миллионов случаев заболеваний костно-мышечной системы (далее - 
КМС) у взрослых. Около 22,1 \% имели болезни суставов, 20,3 \% боли в спине, $17,5 \%$ сообщили о болях в суставах, не связанных с артритом и другими заболевания суставов. Зафиксировано 14,3 \% случев болей в шейном отделе позвоночника, 9,8 \% случаев боли в результате люмбоишалгии [15]. Распространенность хронических болезней КМС, обнаруженных среди взрослого населения, на 76 \% больше, чем хронических заболеваний сердечно-сосудистой системы, и вдвое больше, чем хронических заболеваний респираторной системы. Количество болезней КМС составило 54 случая на каждые 100 человек, при этом количество болезней кровеносной системы составило 31 случай на 100 человек, а болезней респираторной системы - 28 случаев на 100 человек. По гендерным различиям среди женщин зафиксировано 56 случаев на каждые 100 человек, у мужчин 51 случай на каждые 100 человек. О проблемах с КМС сообщили 70 \% людей от 65 лет и старше [15].

В Российской Федерации болезни костно-мышечной системы занимают 3 место в структуре заболеваемости населения, уступая заболеваниям дыхательной и сердечно-сосудистой систем. Так, за 2014 г. общая заболеваемость составила 160 864,6 на 100 тыс. человек населения. С 2010 по 2014 г. заболеваемость болезнями костно-мышечной системы повысилась на 647,9 на 100 тыс. человек населения (с 12 815,0 до 13 462,9), причем основная масса больных сосредоточена в крупных городах [2]. Парадокс состоит в том, что именно эти города предоставляют и максимально полные возможности для лечения, реабилитации и профилактики пациентов с заболеваниями опорно-двигательного аппарата. Здесь сосредоточены технологические ресурсы, квалифицированные кадры и медицинские учреждения разных форм собственности, отличающиеся зачастую качеством предоставления услуг.

В муниципальной системе здравоохранения сформировался частный сектор, конкурирующий с государственным и привлекающий часть платежеспособного спроса преимущественно среднего класса. Государственная медицина ориентирована на усредненные стандарты обслуживания населения, ее основные критерии - массовость, доступность, бес- платность. Система обязательного медицинского страхования в целом обеспечивает потребности населения в медицинской помощи в рамках этих стандартов и выполняет свою роль важного элемента социальной защиты граждан Российской Федерации. Но в лечении, реабилитации и профилактике болезней опорно-двигательного аппарата важно соблюдать несколько принципов. Нужно подбирать индивидуальную программу реабилитации для каждого конкретного пациента. В реабилитации должны принимать участие врачи разных специальностей, такие как неврологи, травматологи, терапевты, врачи лечебной физкультуры, физиотерапевты, массажисты, мануальные терапевты, медицинские психологи. Реабилитация должна проходить непрерывно, в соответствии с разработанной индивидуальной программой в течение длительного времени. Все эти принципы зачастую не входят в систему стандартов и, следовательно, не оплачиваются по системе обязательного медицинского страхования. Потребность городского населения в лечении и качественной реабилитации болезней опорно-двигательного аппарата послужила интенсивному развитию платных медицинских услуг в этой сфере. В крупных городах сейчас сосредоточено множество частных медицинских организаций, оказывающих разноплановые услуги в плане лечения и реабилитации, что, безусловно, можно оценить как позитивное влияние городской среды на здоровье.

Рост доходов населения обусловил появление категории граждан, формирующих платежеспособный спрос на медицинские услуги более широкого спектра с высокой сервисной составляющей. Это служит интенсивному развитию платных услуг в здравоохранении, сектор которых из года в год демонстрирует устойчивый рост $[3 ; 13]$.

По данным Росстата, среднесписочная численность работников здравоохранения в частных организациях с каждым годом растет. Так, в 2005 г. количество работников частной сферы здравоохранения составляло $4 \%$ от общего числа, в 2014 г. их стало в 2 раза больше - 7,9 \%. В 2014 г. число больничных организаций с частной формной собственности составило 166 из 5638, или $3 \%$. Мощность частных амбулаторно-поликлинических уч- 
реждений (тыс. посещений в смену) составила $7 \%$ мощности всех таких учреждений в стране. В 2010 г. было всего 4 \% [7]. Государственная статистика до сих пор не собирает данные об объеме деятельности частных медицинских организаций, о численности обслуженных ими пациентов. Судить об этом можно лишь по данным маркетинговых и социологических исследований.

Коммерческая медицина стала единственным растущим сегментом на рынке услуг с 2014 по 2016 год. По данным «РБК Исследования рынков», в 2015 г. объем рынка платных медицинских услуг в абсолютном выражении составил 671,5 млрд руб., что на 9,1 \% выше показателя предыдущего года. В первом квартале 2016 г. объем платных услуг в медицине увеличился на 4,3\% по сравнению с аналогичным периодом 2014 г. [11].

По данным «РБК Исследования рынков» на апрель 2016 г., в структуре рынка частной медицины за 2016 г. 43,3 \% составили диагностические услуги; 31,2 \% - многопрофильные клиники; 15,2 \% - стоматологические услуги; 9,3\% - урология, гинекология, акушерство; $0,8 \%$ - мануальная терапия; $0,2 \%$ - косметология; $0,1 \%$ - лазерная терапия [11].

По оценкам руководителей частных организаций, в 75,5\% из них оказывают медицинские услуги, предоставляемые в государственных учреждениях. Вместе с тем в $1 / 4$ частных медицинских организаций оказывают услуги, которые не предоставляются в государственных учреждениях, работающих на этой же территории. За исключением различных услуг в области косметологии, это, как правило, различные методы диагностики и лечения, основанные на новых медицинских технологиях. В абсолютном большинстве частных медицинских организаций (93 \%) численность работающих менее 100 человек. Лишь в 1,6 \% организаций было занято больше 250 человек. Подсчитать количество негосударственных медицинских учреждений в Волгоградской области, как, впрочем, и в других субъектах РФ, достаточно сложно. Не существует единой базы данных по частным клиникам, вдобавок некоторые из них существуют в течение короткого промежутка времени. Судить об их количестве можно только по данным различных информационных меди- цинских сайтов. Информация на них создается и добавляется самими руководителями и работниками частных клиник. Можно лишь судить о приблизительном количестве этих клиник и их профильности. По данным информационного портала prodoktorov.ru, только в Волгограде на данный момент зарегистрированы 51 медицинский центр и клиника, 5 гинекологических клиник, 6 глазных клиник, 9 оздоровительных клиник (в числе которых есть клиники по лечению проблем с опорно-двигательным аппаратом), 9 специализированных клиник (из которых 4 клиники специализируются на лечении проблем с опорно-двигательным аппаратом), 6 детских клиник, 7 диагностических центров, 12 лабораторий, 5 косметологических клиник и 110 стоматологических клиник [8].

Таким образом, город помогает человеку справиться с болезнью, которую сам спровоцировал. Но насколько успешно?

Мы провели исследование с целью определить эффективность существующей в крупных городах конкуренции в оказании помощи людям с заболеваниями опорно-двигательного аппарата. В исследовании применялись количественные методы социологии (анкетирование). Было опрошено 360 пациентов частных медицинских клиник, специализирующихся на лечении и реабилитации заболеваний опорно-двигательного аппарата в городах Волжском и Волгограде. Опрос проводился в период с 01.08.2017 по 01.10.2017. В опросе принимали участие пациенты старше 18 лет. Респондентам было предложено заполнить разработанную для целей данного исследования анкету, которая включала 18 вопросов относительно социального положения, медицинской помощи, которую они получали ранее и ее эффективности, а также их мнения по поводу оказания услуг в частных клиниках. Представленные ниже данные округлены до целых чисел.

Распределение горожан в зависимости от пола свидетельствует о том, что в частные медицинские организации, занимающиеся лечением и реабилитацией болезней опорно-двигательного аппарата, как и в государственные, чаще обращаются лица женского пола (58 \%). Но доля мужского населения здесь $42 \%$, что относительно выше других медицинских про- 
филей, например, в стоматологии мужчины составляют лишь 1/3 пациентов. Это, скорее всего, связано с тяжелым физическим трудом и большой нагрузкой на опорно-двигательный аппарат у мужчин. Распределение по возрасту показало, что за медицинской помощью чаще обращаются пациенты в возрасте от 3954 лет (41\%) и пациенты старше 55 лет (27\%).

Большинство опрошенных пациентов занимают высокое социальное положение, имея высшее образование (33 \%), другие занимаются предпринимательской деятельностью (14\%) или являются неработающими пенсионерами (27\%). Остальные категории населения представлены в меньшей степени. Например, служащие без высшего образования составили $8 \%$, студентов оказалось $5 \%$.

Большинство заболеваний опорно-двигательного аппарата протекают длительно и не всегда люди обращаются за помощью при появлении первых симптомов болезни. Более $1 / 3$ опрошенных пациентов (36 \%) имеют проблемы с опорно-двигательным аппаратом от 1 месяца до полугода. Чуть меньше (около $30 \%$ от полугода до трех лет. Четверть пациентов считают себя больными более трех лет. И всего $8 \%$ респондентов указали, что имеют проблемы с опорно-двигательным аппаратом менее 1 месяца.

При изучении уровня и структуры обращаемости населения в частную клинику важно выяснить, где ранее респонденты получали медицинскую помощь по лечению болезней опорно-двигательного аппарата и как они ее при этом оценивают. 2/3 пациентов до момента опроса уже проходили курсы лечения в других медицинских организациях.

Чаще всего (в 60 \% случаев) они обращались в государственные медицинские организации, 36 \% в частные, остальные 4 \% обращались к так называемым народным целителям. Результатами оказываемой помощи в этих организациях остались довольны чуть больше половины, остальных не удовлетворили услуги, оказываемые в этих местах. Таким образом, свыше 60 \% пациентов даже не пытались обращаться в государственные медицинские организации, а сразу обратились в частные или занимались самолечением.

В нашей анкете одной из целей было выяснить причины обращения респондентов в изучаемую частную клинику. Мнение пациентов о медицинской организации зависит от качества обслуживания. Информация о «хорошей» либо «плохой» клинике моментально распространяется среди населения и влияет на ее репутацию. Около $45 \%$ пациентов обратились в данную медицинскую организацию в связи с хорошей репутацией. $26 \%$ по совету знакомых и родственников, которые ранее лечились в данной организации. Реклама в средствах массовой информации оказалась не столь эффективной, всего $22 \%$ респондентов увидели рекламные объявления и решили обратиться в данную медицинскую организацию.

Цены на медицинские услуги в частных организациях складываются из арендной платы, налогов, трат на расходные материалы, заработной платы медицинского персонала, и в сумме получается, что посещение частного специалиста могут себе позволить далеко не все. Но все же люди готовы платить, хоть и завышенную цену, за качественное оказание медицинской помощи, за вежливое обращение и возможность выбрать удобное время для посещения. И если эти условия соблюдаются, то многие пациенты и в дальнейшем обращаются в эту же медицинскую организацию. Около 30 \% респондентов уже лечились в исследуемой клинике и пришли вновь. Остальные 70 \% обратились в первый раз.

Всего $5 \%$ респондентов отметили, что цены на оказываемые услуги были приемлемы для них. Для большинства же (60 \%) услуги частных специалистов высоки, но доступны. Для $22 \%$ цены оказались недоступными. 11 \% имели затруднения с выбором ответа.

$18 \%$ указали, что прерывали лечение изза отсутствия желаемого эффекта. Около $15 \%$ прерывали курс лечения из-за отъезда, обострения или появления сопутствующих заболеваний. $9 \%$ отметили, что им не хватает времени на лечение. Некоторые пациенты (15\%) отметили, что прерывали лечение в связи с разногласиями с лечащим врачом, $5 \%$ из-за высокой стоимости. Только $40 \%$ респондентов завершали курсы лечения до конца.

Вероятно, это связано с тем, что наряду с лекарственными препаратами, которые пациент может принимать самостоятельно (и это не занимает много времени), пациентам назначают немедикаментозные средства. Ши- 
роко назначаются средства и формы лечебной физкультуры как для самостоятельного выполнения, так и групповые занятия, посещение физиотерапевта, массажиста, мануального терапевта и т. д. Обычно курсы назначаются не одномоментно, а последовательно, в соответствии с планом по лечению и реабилитации. По длительности это может занимать от месяца до полугода, все зависит от тяжести состояния. Растягивание лечения на столь долгий срок снижает мотивацию пациента, в результате большинство из них не проходят лечение до конца и не получают желаемого эффекта.

В процессе анкетирования мы попытались выяснить мнение самих пациентов относительно эффективности оказания медицинской помощи, достоинств и недостатков работы частных клиник. В первую очередь важно было узнать, что же, по мнению респондентов, является наиболее важным для эффективного выздоровления. Около 15 \% пациентов затруднились отвечать на вопросы такого характера. Почти 32 \% пациентов отметили важность наличия квалифицированных специалистов. $16 \%$ считают, что залогом успешного излечения может являться хорошее техническое оснащение. В реабилитации болезней опорно-двигательного аппарата важно самостоятельное выполнение лечебной физкультуры, соблюдение профилактики, и $21 \%$ отметил, что нужно активное участие пациента и желание выздороветь. Респондентам был задан также вопрос относительно причин отсутствия эффекта от лечения. $34 \%$ отметили, что положительного эффекта после лечения может не быть, если курс лечения доведен не до конца. $31 \%$ предположил, что эффект может отсутствовать из-за недостаточной квалификации специалистов. 18 \% затруднились отвечать на этот вопрос.

Респондентам было предложено выбрать достоинства и недостатки лечения в частных медицинских организациях. Среди достоинств частных клиник респонденты выделили высокую квалификацию специалистов (39\%), хорошее материальное оснащение (22 \%), рациональную организацию предоставляемых медицинских услуг (11\%). Адекватность ценообразования отметили всего $4 \%$ пациентов. В государственных клиниках вра- чи имеют высокую квалификацию и обладают хорошими знаниями, но ограничены во времени в связи с высокой нагрузкой, связаны стандартами и бюрократическими правилами. Врач частной клиники заинтересован в том, чтобы пациент стал лечиться именно у него. Он имеет больше времени на общение с пациентом, может использовать все средства и методы, которые имеются в данной клинике. Поэтому работу врача частной клиники пациенты оценивают высоко.

Из минусов в работе частных клиник самым большим недостатком оказались завышенные цены на предоставляемые услуги. Этот пункт выбрали 44 \% респондентов. Низкую квалификацию отметили всего 8 \%, 26 \% не смогли дать однозначного ответа.

Несмотря на высокую ценовую политику исследуемой частной медицинской организации, $64 \%$ опрошенных пациентов готовы рекомендовать ее посещение своим родным и близким. Всего 11 \% выбрали отрицательный вариант ответа, и $25 \%$ испытали затруднение в ответе на вопрос.

И в конце мы попытались выяснить, что, по мнению респондентов, является залогом успешного излечения болезней опорно-двигательного аппарата. Примерно 1/3 пациентов отметили важность следования всем указаниям врача и доведение курса лечения до конца. $26 \%$ считают, что для положительного результата важно применение как новых, так и старых, хорошо зарекомендовавших себя технологий, в том числе методов народной медицины. Всего 5 \% выбрали в качестве ответа удачный выбор клиники, и 8 \% удачный выбор специалистов. Около 12 \% испытали затруднение в ответе на поставленный вопрос.

В большинстве случаев пациенты частных медицинских клиник уже лечились в государственных медицинских организациях или самостоятельно и не получили желаемого эффекта. Большую часть пациентов составляют состоятельные граждане. Часто они признают, что цена на услуги частных специалистов завышена, но готовы ее платить. Пациент готов обращаться только в проверенные клиники, у которых хорошая репутация, или по совету родных и близких. Люди хотят, что бы их лечил квалифицированный специалист. Они выбирают клинику с хорошим техническим ос- 
нащением. Респонденты отметили, что важно доводить курс лечения до конца и следовать всем указаниям врача.

На основе полученных данных можно заключить, что преимущества городской среды в борьбе с заболеваниями опорно-двигательного аппарата, которые она сама часто и порождает, заключаются в следующем:

1. Наличие в городе достаточно большого числа хороших клиник (квалифицированные специалисты + высокотехнологичное оборудование), как государственных, так и частных, что обеспечивает свободу выбора для пациента.

2. Наличие средств у пациентов для оплаты лечения и реабилитации в частных клиниках.

3. Наличие конкуренции между клиниками, что стимулирует повышение качества оказания медицинской помощи.

Таким образом, городская среда содержит патогенные факторы, провоцирующие рост числа заболеваний опорно-двигательного аппарата, но она же предлагает методы: а) лечения (государственные клиники, частные клиники, фармацевтические услуги); б) реабилитации (государственные клиники, частные клиники, фармацевтические услуги, спортивные комплексы, фитнес-центры); в) профилактики (спортивные комплексы, фитнес-центры и т. п.). Проблема заключается в том, выберет ли сам человек оздоравливающие компоненты городской среды или те, которые могут играть роль патологических агентов. Согласно полученным нами данным, реабилитационные мероприятия для городских жителей обходятся недешево, поскольку приоритет в оказании такого рода услуг принадлежит частным клиникам и центрам. Они, несомненно, заинтересованы не только в улучшении качества жизни своих клиентов, но они заинтересованы и в доходах от своей деятельности. Возникающее в этой ситуации противоречие целей может быть разрешено только с помощью государства, которое должно активно развивать социальные технологии здорового образа жизни и профилактические практики.

\section{СПИСОК ЛИТЕРАТУРЫ}

1. Горина, Е. А. Взгляд на качество жизни населения сквозь призму городской среды / Е. А. Го- рина, А. Я. Бурдяк // Социология города. - 2015. № 2. - C. 11-31.

2. Здравоохранение в России. 2015 : стат. сб. М. : Федер. служба гос. статистики, 2015. - 174 с.

3. Климин, В. Г. Финансово-организационный механизм солидарного медицинского страхования : дис. ... канд. экон. наук / Климин Владимир Григорьевич. - Екатеринбург, 2007. - 203 с.

4. Кожевников, А. А. Функциональный анализ здоровья городского населения / А. А. Кожевников, В. А. Пилипенко // Социология города. 2016. - № 2. - C. $72-80$.

5. Комаров, Ю. М. Влияние городской среды на здоровье населения / Ю. М. Комаров, И. Н. Веселкова // Врачебная газета. - 2000. - № 9. - С. 18.

6. Кураков, Д. А. Гиподинамия - результат урбанизации или лени? (По материалам медико-социологического исследования) / Д. А. Кураков, Н. Л. Мальцева // Социология города. - 2014. № 3. - C. $74-81$.

7. Медведева, Л. М. Человек и болезнь: виновен или не виновен? / Л. М. Медведева, Р. Н. Морозов // Биоэтика. - 2011. - Т. 1, № 7. - С. 41-42.

8. Медицина Волгограда. - Электрон. текстовые дан. - Режим доступа: https://prodoctorov.ru/ volgograd/ (дата обращения: 23.12.2017). - Загл. с экрана.

9. Навроцкий, Б. А. Город как предмет интереса российских социологов (заметки о V Всероссийском социологическом конгрессе) / Б. А. Навроцкий // Социология города. - 2016. - № 4. - С. 5-9.

10. Навроцкий Б. А. Проблемы биоэтики в социологических исследованиях городской тематики / Б. А. Навроцкий, В. В. Деларю // Биоэтика. - 2014. № 1. - C. 31-33.

11. Платные Медицинские услуги // Журнал РБК 09/2016. - Электрон. текстовые дан. - Режим доступа: $\mathrm{http}: / /$ www.rbcplus.ru/issue/57b8181e7a8aa 9359d031a10 (дата обращения: 23.12.17). - Загл. с экрана.

12. Седова, Н. Н. «Городские» риски мужского здоровья / Н. Н. Седова, С. А. Щелков // Социология города. -2014 . - № 1. - С. 3-12.

13. Фоменко, В. В. Актуальные проблемы финансирования национального здравоохранения / В. В. Фоменко // Фундаментальные исследования. -2013 . - № 10 (ч. 4) - С. 841-845.

14. Nevinskij, A. B. The roundtable discussion: ethical problems of children's vaccination against influenza/A. B. Nevinskij, L.V. Kramar, B. A. Navrotskiy // Bioethics. - 2016. - № 1 (17). - P. 62-64.

15. Use of Complementary Health Approaches for Musculoskeletal Pain Disorders Among Adults: United States, 2012 / T. C. Clarke, R. L. Nahin, P. M. Barnes, B. J. Stussman // National Health Statistics Reports. 2016. - № 98. - P. 1-9. 
16. Zhuzhlova, N. Yu. Interpretation of the availability of medical care for patients with arterial hypertension in the context of the principle of justice / N. Yu. Zhuzhlova, I. L. Krom, G. Yu. Sazanova // Bioethics. - 2016. - № 1 (17). - P. 46-49.

\section{REFERENCES}

1. Gorina E.A., Burdyak A.Ya. Vzglyad na kachestvo zhizni naseleniya skvoz prizmu gorodskoy sredy [Life Quality in the Urban Environment]. Sotsiologiya goroda, 2015, no. 2, pp. 11-31.

2. Zdravookhranenie v Rossii. 2015: stat. sb. [Healthcare in Russia. 2015: Statistical Compilation]. Moscow, Rosstat Publ., 2015. 174 p.

3. Klimin V.G. Finansovo-organizatsionnyy mekhanizm solidarnogo meditsinskogo strakhovaniya: dis. ... kand. ekon. nauk [Financial and Organizational Mechanism of the Joint Medical Insurance. Cand. econ. sci. diss.]. Ekaterinburg, 2007.203 p.

4. Kozhevnikov A.A., Pilipenko V.A. Funktsionalnyy analiz zdorovya gorodskogo naseleniya [Functional Analysis of Health of the Population]. Sotsiologiya goroda, 2016, no. 2, pp. 72-80.

5. Komarov Yu.M., Veselkova I.N. Vliyanie gorodskoy sredy na zdorovye naseleniya [Influence of Urban Environment on Public Health]. Vrachebnaya gazeta, 2000, no. 9, p. 18.

6. Kurakov D.A., Maltseva N.L. Gipodinamiya rezultat urbanizatsii ili leni? (Po materialam medikosotsiologicheskogo issledovaniya) [Hypodinamy is the Result of Urbanization or Laziness? (Based on the Materials of Medical and Sociological Research)]. Sotsiologiya goroda, 2014, no. 3, pp. 74-81.

7. Medvedeva L.M., Morozov R.N. Chelovek i bolezn: vinoven ili ne vinoven? [Man and Illness: Guilty or Innocent?]. Bioetika, 2011, vol. 1, no. 7, pp. 41-42.
8. Meditsina Volgograda [The Medicine of Volgograd]. URL: https://prodoctorov.ru/volgograd. (accessed December 23, 2017).

9. Navrotskiy B.A. Gorod kak predmet interesa rossiyskikh sotsiologov (zametki o V Vserossiyskom sotsiologicheskom kongresse) [A City as a Subject of Russian Sociologists' Interest (Notes on the $5^{\text {th }}$ AllRussian Sociological Congress)]. Sotsiologiya goroda, 2016, no. 4, pp. 5-9.

10. Navrotskiy B.A., Delaryu V.V. Problemy bioetiki $\mathrm{v}$ sotsiologicheskikh issledovaniyakh gorodskoy tematiki [Problems of Bioethics in Sociology of City Themes]. Bioetika, 2014, no. 1, pp. 31-33.

11. Platnye Meditsinskie uslugi [Paid Medical Services]. Zhurnal RBK, 2016, pp. 94-103. URL: http:// www.rbcplus.ru/issue/57b8181e7a8aa9359d031a10. (accessed December 23, 2017).

12. Sedova N.N., Shchelkov S.A. «Gorodskie» riski muzhskogo zdorovya ["City" Men's Health Risks]. Sotsiologiya goroda, 2014, no. 1, pp. 3-12.

13. Fomenko V.V. Aktualnye problemy finansirovaniya natsionalnogo zdravookhraneniya [Current Problems of Financing the National Health Care System]. Fundamentalnye issledovaniya, 2013, no. 10 (part 4), pp. 841-845.

14. Nevinskij A.B., Kramar L.V., Navrotskiy B.A. The roundtable discussion: ethical problems of children's vaccination against influenza. Bioethics, 2016, no. 1 (17), pp. 62-64.

15. Clarke T.C., Nahin R.L., Barnes P.M., Stussman B.J. National Institutes of Health. Use of Complementary Health Approaches for Musculoskeletal Pain Disorders Among Adults: United States, 2012. National Health Statistics Reports, 2016, no. 98, pp. 1-9.

16. Zhuzhlova N.Yu., Krom I.L., Sazanova G.Yu. Interpretation of the availability of medical care for patients with arterial hypertension in the context of the principle of justice. Bioethics, 2016, no. 1 (17), pp. 46-49.

\section{Information about the Authors}

Evgeniy G. Vershinin, Candidate of Medical Sciences, Associate Professor, Head of Department of Medical Rehabilitation and Sports Medicine with the Course of Medical Rehabilitation, Physical Therapy, Sports Medicine, Physiotherapy, Volgograd State Medical University, Pavshikh bortsov Sq., 1, 400131 Volgograd, Russian Federation, werschinin_eugen@list.ru.

Mikhail A. Sukhoruchko, Postgraduate Student, Department of Philosophy, Bioethics and Law with the Course of Sociology of Medicine, Volgograd State Medical University, Pavshikh bortsov Sq., 1, 400131 Volgograd, Russian Federation, mixsyx@mail.ru.

Gennadiy Yu. Shchekin, Doctor of Sociological Sciences, Professor, Department of Philosophy, Bioethics and Law with the Course of Sociology of Medicine, Volgograd State Medical University, Pavshikh bortsov Sq., 1, 400131 Volgograd, Russian Federation, alfa-001@yandex.ru. 


\section{Информация об авторах}

Евгений Геннадьевич Вершинин, кандидат медицинских наук, доцент, заведующий кафедрой медицинской реабилитации и спортивной медицины с курсом медицинской реабилитации, лечебной физкультуры, спортивной медицины, физиотерапии, Волгоградский государственный медицинский университет, пл. Павших Борцов, 1, 400131 г. Волгоград, Российская Федерация, werschinin_eugen@list.ru.

Михаил Александрович Сухоручко, аспирант кафедры философии, биоэтики и права с курсом социологии медицины, Волгоградский государственный медицинский университет, пл. Павших Борцов, 1, 400131 г. Волгоград, Российская Федерация, mixsyx@mail.ru.

Геннадий Юрьевич Щекин, доктор социологических наук, профессор кафедры философии, биоэтики и права с курсом социологии медицины, Волгоградский государственный медицинский университет, пл. Павших Борцов, 1, 400131 г. Волгоград, Российская Федерация, alfa-001@yandex.ru. 